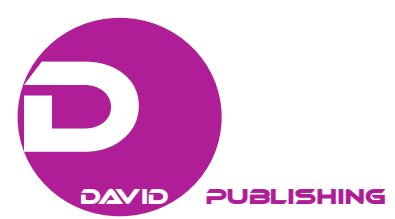

\title{
Asian Trade Integration and the Decoupling Debate of Business Cycles*
}

\author{
Linyue Li \\ Central University of Finance and Economics, Beijing, China \\ Claremont Institute for Economic Policy Studies, Claremont, USA
}

\begin{abstract}
"Decoupling" refers to the divergence of business cycles among different countries, while "re-coupling" corresponds to the convergence or the synchronization of business cycles among different countries. The decoupling debate is popular in the field of economics, especially after global financial crisis. As trade integration increased among Asian countries, business cycle synchronization among these countries was expected to increase through trade transmission. The aim of this study is to discover whether there has been decoupling or convergence of business cycles through various trade channels. However, theoretically, increased trade can lead to business cycle synchronization either rising or falling. Inter-industry trade resulting in higher specification will induce less synchronized business cycles, while intra-industry trade could lead to increased business cycle synchronization. Thus, it is important to distinguish between intra- and inter-industry trade flows. Both correlation and dynamic factor models are utilized to study the evolution of global business cycle linkages. Results indicate that the world factor has become less important in explaining macroeconomic fluctuations from sub-period 1961-1984 to sub-period 1985-2007, while regional factors do not play an important role in explaining aggregate volatility, with the expectation of consumption. Overall, the explanatory power of country factors increases. Domestic consumption and domestic investment variances are more driven by country and idiosyncratic factors than by the world factor, contrary to the output growth fluctuations. Regional factors and country factors also play a more prominent role in explaining gross import fluctuations than in explaining gross exports. Results cast doubt on the strong forms of both the decoupling and the re-coupling hypothesis.
\end{abstract}

Keywords: trade integration, decoupling, business cycle, dynamic factor model, world factor

\section{Introduction}

Over the past decades, there has been considerable debate about how the US economy affects other countries, through spillovers and business cycle transmission in the global economy. The old adage is that "when the US sneezes, the rest of the world catches a cold", which vividly indicates the significance that spillovers from US fluctuations have on other economies. However, the performance of emerging economies

\footnotetext{
* Project Supported: The paper is supported by National Natural Science Foundation of China (NSFC) and the Fundamental Research Funds for the Central Universities.

Linyue Li, assistant professor, Central University of Finance and Economics, Beijing, China; senior researcher, Claremont Institute of Economic Policy Studies, Claremont, USA.

Correspondence concerning this article should be addressed to Linyue Li, No. 39, South College Road, Haidian District, Beijing, 100081, China.
} 
during the global financial crisis, such as China and India, has shaken the role of the US as a key driver of the world economy. This has brought the decoupling debate back into popularity.

Different interpretations of decoupling emerge for different contexts. Generally speaking, there are two versions of decoupling hypothesis. One version is that emerging markets, such as China, India, and Malaysia, could be decoupled from the advanced economies, such as the United States, the EU, and Japan. The other is that Asian economies including Japan could be decoupled from the United States. Under the background of East Asian exports in the global economic crisis, the concept of decoupling refers to "the notion that the East Asia region had become a self-contained economic entity with potential for maintaining its own growth dynamism independent of the economic outlook for the traditional developed market economies" (Athukorala $\&$ Kohpaiboon, 2009). For example, during the Great Recession, in advanced economies such as the EU and the US, emerging markets such as China and India have been able to insulate their economies better than most of others (Willett, Thomas, Liang, \& Zhang, 2011). In fact, the switching between decoupling and re-coupling views is highly alarming, because it is based on the time horizon and the patterns of shocks (Willett et al., 2011).

In East Asian economies, an export-oriented growth path highlights trade as a leading candidate of transmission. However, there is still a lot of uncertainty around its true influence. Would it be possible for emerging Asian economies to be decoupled from the EU and the US? Do greater trade flows between two countries increase their business cycle synchronization? To further analyze these questions, both standard approaches and dynamic factor models are employed, and data from 11 Asian countries, the Eurozone, and the United States (US) are used to discuss trade integration and business cycle synchronization.

For the research design, analysis begins with a comparison of conventional correlations of real GDP growth rates for each pair of countries, using simple correlations without de-trending and correlations of the deviations from the trend. Increasing correlations among ASEAN countries and decreasing correlations between Asian countries and the US and Eurozone are expected in the process of business cycle evolution. However, conventional correlations are static, contemporaneous, and cannot capture interactive effects of propagation and spillovers from shocks, compared with a dynamic factor model. Also, simple before-and-after comparisons do not give an accurate picture of the degree of convergence or decoupling of business cycles, because similar increases or decreases could occur due to common factors for which conventional correlations cannot control.

\section{Materials and Methods}

Generally speaking, existing literature on decoupling is primarily based on five types of methodologies: correlation approaches, dynamic factor models, cointegration approaches, structural macro econometric models, and vector autocorrelation (VAR) impulse response functions. Typically, correlation approaches involve a series of bivariate correlations, while dynamic factor models distinguish among global factors, region-specific factors, country factors, and idiosyncratic factors.

There are questions about whether the estimation results of the Frankel-Rose truly indicate trade's role in shock transmission, or if they are instead driven by omitted variables, such as common shocks that happen to be stronger for countries that trade more with each other (Giovanni di \& Levchenko, 2009). A competing hypothesis is that countries comove simply due to their correlated shocks. The common shock theory argues that it cannot just be due to international trade. It holds that if industries are truly hit by common global 
technology or demand shocks, comovement will occur even in the complete absence of trade transmission.

This debate is troubling because it is very difficult to sort out the relative importance of the transmission and common shock channels within country-level data, or to estimate either one of them reliably. For instance, the positive relationship between overall bilateral trade and comovement (Frankel \& Rose, 1998) or between intra-industry trade and comovement is not conclusive evidence of transmission, since it may be driven by the omitted common shocks (Giovanni di \& Levchenko, 2009). Dynamic factor models evolved to fit this gap.

Kose, Otrok, and Prasad (2008) distinguished the roles played by global cycles from cycles common to specific groups of countries: industrial economies, emerging markets, and other developing countries. They decompose macroeconomic fluctuations in national output, consumption, and investment into the following factors: 1) the global factor, which picks up fluctuations that are common across all variables and countries; 2) group specific factors, which capture fluctuations that are common to all variables and all countries in a given group; 3) country specific factors, which are common across all variables in a given country; and 4) idiosyncratic factors, which are specific to each time series, and are residual, not explained by other factors.

The research by Kose et al. (2008) provides a valuable analysis of the evolution of the degree of the global business cycle linkages over the period of 1960-2005, by using a dynamic factor model. The major finding indicates some convergence of business cycle fluctuations among the group of emerging market economies and among the group of industrial economies, during the period of globalization (1985-2005). Surprisingly, as globalization deepens, there has been a concomitant decline in the relative importance of the global factor in explaining the macroeconomic fluctuations of output, domestic consumption, and domestic investment. In other words, there is evidence of business cycle convergence within the group of emerging market economies and the group of industrial economies, but also simultaneous divergence between these groups.

To employ a Bayesian Dynamic Latent Model, 11 countries within the Asian region were chosen, including the 10 major emerging economies in Asia: China (mainland), Taiwan, Hong Kong, Singapore, South Korea, India, Indonesia, Malaysia, the Philippines, and Thailand, and one industrialized economy: Japan. Two versions for advanced economies are considered: one version is that whether advanced economies, including Japan, affect Asian emerging economies, and the other is that whether the EU and the US affect Asian economies.

Similar to the work done by Kose et al. (2008), macroeconomic fluctuations were decomposed into domestic output, which is measured by the growth of GDP, domestic consumption, domestic investment, gross exports, and gross imports, separated into the following factors:

1. The global factor, which considers fluctuations that are common across all variables and countries;

2. Group-specific factors, which capture fluctuations that are common to all variables and all countries in a given group;

3. Country-specific factors, which are common across all variables in a given country;

4. Idiosyncratic factors specific to each time series, which are residual, not explained by other factors.

In practice, each series was logged first, then taken first order difference and demeaned by Hodrick-Prescott filter or simple average (as in Otrok \& Whiteman, 1998).

Observable variables are denoted by:

$$
\begin{gathered}
Y_{i t}, \text { for } i=1,2,3, \ldots, M^{*} N, t=1,2,3, \ldots, T \\
Y_{i t}=\alpha_{i}+b_{i}^{\text {World }} f_{t}^{\text {World }}+b_{i}^{\text {Region }} f_{r t}^{\text {Region }}+b_{i}^{\text {Country }} f_{i t}^{\text {Country }}+\varepsilon_{i t}
\end{gathered}
$$




$$
\begin{gathered}
E \varepsilon_{i t} \varepsilon_{j, t-s}=0 \text { for } i \neq j ; r=1,2,3 \text { (3 regions); } 28 \text { countries } \\
\operatorname{Var}\left(Y_{i t}\right)=\left(b_{i}^{\text {World }}\right)^{2} \operatorname{Var}\left(f_{t}^{\text {World }}\right)+\left(b_{i}^{\text {Region }}\right)^{2} \operatorname{Var}\left(f_{r t}^{\text {Region }}\right)+\left(b_{i}^{\text {Country }}\right)^{2} \operatorname{Var}\left(f_{i t}^{\text {Country }}\right)+\operatorname{Var}\left(\varepsilon_{i t}\right)
\end{gathered}
$$

where $Y_{i t}$ is a Q-dimensional vector of the covariance stationary time series at time $t(t=1,2,3, \ldots, T)$ for country $i\left(i=1,2,3, \ldots, M^{*} N\right) . M$ is the number of time series per country (e.g. if growth rate of output, consumption, and investment in a set of countries are a three-dimensional vector of $Y_{i t}, M=3$ ); $N$ is the number of countries. And $f_{t}^{\text {World }}$ denotes a world factor for all countries, $f_{r t}^{\text {Region }}$ denotes region-specific factors or regional factors for each region and $f_{i t}$ Country denotes country-specific factors for each country. To identify the regional factor of the US, two contingent countries, Canada and Mexico were added to the system. The results of Canada and Mexico are not reported, because they are not the focus here.

The fraction due to the region-specific factor, for example, would be:

$\left[\left(b_{i}^{\text {Region }}\right)^{2} \operatorname{Var}\left(f_{r t}^{\text {Region }}\right)\right] / \operatorname{Var}\left(Y_{i t}\right)$, which are similar to the case of Asian countries.

Since recent studies using dynamic factor models only focus on domestic macroeconomic variables representing the real side of the domestic economy, leaving out trade, exports, and imports are added in the $Y_{i t}$ vector to find the contributions each factor has on the fluctuations through trade transmission.

Table 1

Data Descriptions

\begin{tabular}{lllll}
\hline Variables & Description & Sources & Frequency & Estimated period \\
\hline$Y_{i t}, Y_{j t}$ & Gross domestic production & PWT & Annual & $1960-2007$ \\
$X_{i t}, X_{j t}$ & Multiple exports & DOT, CEPD & Annual & $1980-2008$ \\
$M_{i t}, M_{j t}$ & Multiple imports & DOT, CEPD & Annual & $1980-2008$ \\
$C_{i t}, C_{j t}$ & Domestic consumption & PWT & Annual & $1960-2007$ \\
$I_{i t}, I_{j t}$ & Domestic investment & PWT & Annual & $1960-2007$ \\
\hline
\end{tabular}

Note. CEPD (Council for Economic and Planning Development) is for the data of Taiwan.

Table 1 presents the main variables used in the model. This study utilizes empirical framework estimations with annual data (panel structure) in three sub-periods: 1976-1984, 1985-1996 (1989 or 1990 may be used instead of 1985, but for better comparison with Kose et al.'s (2008) work, the author chose 1985), and 1997-2007 or 1999-2007 (excluding the 97-98 Asian Crisis to capture an ideal long-term trend without abnormal shocks). The Asian Crisis in 1997-1998 and the Information and Communication Technology (ICT) bubble burst in 2000-2001 were considered, which could be breaking points in hypothesis testing, because they may distort the data and exaggerate conventional measures of business cycle co-movement. Another possible testing point could be 1992, the year AFTA (Asia Free Trade Area) was established. Rationale for choosing year 1985 as the first dividing point, similar to Kose et al. (2008), is that global trade and financial flows have increased markedly since the mid-1980s. The beginning of the globalization period coincides with a structural decline in the volatility of business cycles in both industrialized and non-industrialized countries. The year 1997 was chosen as the second dividing point due to the occurrence of the Asian Crisis.

To calculate an intra-industry trade index for the Eurozone in the three sub-periods, eight major countries were chosen as representatives if no aggregate data were available, considering the changing members of the Eurozone over time. These eight countries are Austria, Finland, France, Germany, Ireland, Italy, Netherland and Spain, which originally joined the Eurozone in 1999. This is because deepening trade histories and relatively large market sizes have helped these original eight countries dominate in the Eurozone. Another 
reason is that other small regions or countries will not have as much impact as the major eight countries.

This study did not separate fixed and flexible exchange rate regimes, for two reasons. First, as mentioned by Kose et al. (2008), there is no conclusive evidence that splitting the sample in this way is beneficial. For instance, while some economists believe that different types of exchange rate regimes do not result in significant changes in the behavior of the main macroeconomic aggregates, others have concluded that exchange rate regimes have a significant impact on stylized business cycle characteristics. Second, the available measures of exchange rate regimes have been subject to considerable controversy (Baxter \& Kouparitsas, 2005). This is a topic for future research.

\section{Empirical Results of Correlations}

Generally speaking, business cycle correlations are heavily influenced by patterns of shocks, which can vary greatly over time and then affect the correlations again through various channels of transmission. Tables 2 and 3 representing the correlations of real GDP growth for intra-Asia or Asia versus the US or the Eurozone quantitatively reflect the instability and potential linkages.

As previously mentioned, non-detrended simple correlations of real GDP growth in the short run, such as the one year growth rate, serve as a relatively reasonable measure for judging whether there is convergence or decoupling. Since long-term horizons, such as six years, accumulate differences in growth that are not clearly visible on the annual basis, they will become prominent in long run growth. Therefore, it is not sensible to use simple correlations of real GDP growth in five-year interval or more than five-year interval alone for analysis, without comparing with the related correlations of the deviations from the trend.

Table 2

Correlations of Real GDP Growth 1976-1980

\begin{tabular}{|c|c|c|c|c|c|c|c|c|c|c|c|c|}
\hline & $\mathrm{CHN}$ & HKG & INDIA & INDO & JPN & KOR & MLS & PHL & SGP & THA & TWN & USA \\
\hline $\mathrm{CHN}$ & 1.000 & & & & & & & & & & & \\
\hline HKG & -0.625 & 1.000 & & & & & & & & & & \\
\hline INDIA & 0.999 & -0.666 & 1.000 & & & & & & & & & \\
\hline INDO & -0.704 & 0.994 & -0.742 & 1.000 & & & & & & & & \\
\hline JPN & -0.524 & 0.992 & -0.569 & 0.974 & 1.000 & & & & & & & \\
\hline KOR & 1.000 & -0.622 & 0.998 & -0.701 & -0.520 & 1.000 & & & & & & \\
\hline MLS & -0.301 & 0.933 & -0.353 & 0.889 & 0.970 & -0.297 & 1.000 & & & & & \\
\hline PHL & -0.304 & 0.934 & -0.356 & 0.891 & 0.971 & -0.300 & 1.000 & 1.000 & & & & \\
\hline SGP & -0.691 & 0.996 & -0.729 & 1.000 & 0.978 & -0.688 & 0.898 & 0.899 & 1.000 & & & \\
\hline THA & -0.306 & 0.934 & -0.357 & 0.891 & 0.971 & -0.302 & 1.000 & 1.000 & 0.900 & 1.000 & & \\
\hline TWN & -0.697 & 0.995 & -0.735 & 1.000 & 0.976 & -0.694 & 0.894 & 0.895 & 1.000 & 0.896 & 1.000 & \\
\hline USA & 0.236 & 0.612 & 0.183 & 0.524 & 0.704 & 0.240 & 0.856 & 0.854 & 0.540 & 0.853 & 0.532 & 1.000 \\
\hline
\end{tabular}

Notes. Data sources are International Monetary Fund (IFS), World Economic Outlook (WEO), and Council for Economic and Development Planning for Taiwan data. Data for Eurozone from 1976 to 1991 are not available.

First, there is existing evidence of the convergence of business cycles in ASEAN countries. For example, from 1976-1980 (see Table 2), the simple correlations for pairs Indonesia versus Singapore, Malaysia versus Thailand, the Philippines versus Thailand, and Malaysia versus the Philippines approached 1, when rounded to three-digit numbers. All of the ASEAN countries kept high correlations with each other, 0.889 for Indonesia versus Malaysia, 0.891 for Indonesia versus the Philippines and Indonesia versus Thailand, 0.898 for Malaysia 
versus Singapore, and 0.900 for Singapore versus Thailand. During 1981-1984, although the strong correlations among ASEAN countries were weakened to some extent, the country pairs of Indonesia versus Malaysia, Indonesia versus Singapore, Indonesia versus Thailand, Malaysia versus Singapore, Malaysia versus Thailand, and Singapore versus Thailand still had high correlations, such as 0.526 for Singapore versus Malaysia and 0.987 for Indonesia versus Thailand.

Table 3

Correlations of Real GDP Growth 2006-2009

\begin{tabular}{llllllllllllll}
\hline & CHN & HKG & INDIA & INDO & JPN & KOR & MLS & PHL & SGP & THA & TWN & USA & EUA \\
\hline CHN & 1.000 & & & & & & & & & & & & \\
HKG & 0.865 & 1.000 & & & & & & & & & & & \\
INDIA & 0.915 & 0.972 & 1.000 & & & & & & & & & & \\
INDO & 0.609 & 0.736 & 0.585 & 1.000 & & & & & & & & & \\
JPN & 0.880 & 0.995 & 0.957 & 0.790 & 1.000 & & & & & & & & \\
KOR & 0.911 & 0.995 & 0.986 & 0.711 & 0.992 & 1.000 & & & & & & & \\
MLS & 0.724 & 0.944 & 0.841 & 0.889 & 0.957 & 0.915 & 1.000 & & & & & & \\
PHL & 0.657 & 0.827 & 0.687 & 0.986 & 0.867 & 0.798 & 0.952 & 1.000 & & & & & \\
SGP & 0.929 & 0.982 & 0.997 & 0.645 & 0.975 & 0.995 & 0.871 & 0.738 & 1.000 & & & & \\
THA & 0.808 & 0.993 & 0.938 & 0.780 & 0.990 & 0.976 & 0.974 & 0.868 & 0.952 & 1.000 & & & \\
TWN & 0.971 & 0.958 & 0.981 & 0.663 & 0.960 & 0.982 & 0.841 & 0.737 & 0.990 & 0.919 & 1.000 & & \\
USA & 0.799 & 0.993 & 0.947 & 0.740 & 0.984 & 0.976 & 0.961 & 0.837 & 0.956 & 0.998 & 0.917 & 1.000 & \\
EUA & 0.810 & 0.991 & 0.931 & 0.802 & 0.991 & 0.974 & 0.980 & 0.885 & 0.948 & 0.999 & 0.918 & 0.995 & 1.000 \\
\hline
\end{tabular}

Note. Due to limited space, correlations of real GDP growth in other different sub-periods are omitted here.

Again, during 1985-1988, the number of ASEAN country pair correlations above 0.55 bounced from six cases in the previous period up to 10. This signals that the business cycles of ASEAN countries further converged during this period. During the next period, 1989-1991, the number of correlations above 0.5 for ASEAN declined, indicating there was divergence during this time. But, after the establishment of AFTA in 1992, and especially after the Asian Crisis in 1997-1998, the business cycles of ASEAN countries converged again. This is especially true after the years of the Asian Crisis and the recent global financial crisis in 2008-2009.

Second, during 1997-2000, ASEAN countries had very high correlations with each other, ranging from 0.769 to 0.996 . However, during this time the correlations of Asian countries with the US and the Eurozone were very low, with the exception of India versus the US, which indicates that the impact of the Asian Crisis did not spread to the US and the Eurozone. The low correlations of Asian countries with the US and the Eurozone signaled the decoupling of Asian countries from the US and the Eurozone, because of their own large shock. Nevertheless, the evidence is not strong enough to fully support the hypothesis of decoupling of Asian economies from US and Eurozone economies. During the following time periods, there were high correlations of Asian countries and the US in 2001-2005, and with both the US and the Eurozone in 2006-2009 (see Table 3).

Third, in the early stage before the 1997-1998 Asian Crisis, China did not play a critical role in the economic growth among Asian countries, the US, and the Eurozone, which can reflect low correlations with other countries in the system. But after the 1997-1998 Asian Crisis, China has become a key global player, partly due to the trend of vertical integration as a center of component assembler for manufacturing. The importance of China gradually catches up to the importance of Japan, and China and Japan provide sustainable 
power to support the growth of the Asian region as well as the US and the Eurozone. Therefore, some economists argue that Asian economies have been less importantly tied to the US.

Short-term correlations in real GDP growth among Asian countries and the US and Eurozone reflect that most of the numbers for the measurements are quite similar, however, the calculation differences between simple correlations and the correlations of the deviations from the Hodrick-Prescott trend are less than 0.15 in $70 \%$ of the calculations for the US and $52 \%$ for the Eurozone. The calculation differences between simple correlations and correlations of deviations from linear trends are less than 0.15 in $80 \%$ of the calculations for the US and $75 \%$ for the Eurozone. The calculation differences between simple correlations and the correlations of deviations from the Hodrick-Prescott trend are greater than 0.25 in $12.5 \%$ of the calculations for the US and $20.83 \%$ for the Eurozone, while the calculation differences between simple correlations and correlations of deviations from linear trend are greater than 0.25 in $10.42 \%$ of the calculations for the US and $8.33 \%$ for the Eurozone. The maximum difference appears in Korea versus the United States during 1976-1980, with 0.723 as the difference between the simple correlations and the correlations of the deviations from the Hodrick-Prescott trend, and 0.734 as the difference between simple correlations and the correlations of deviations from the linear trend.

The Hodrick-Prescott (HP) filter is a data-smoothing technique that is widely applied to remove short-term fluctuations and reveal long-term trends. Compared with the linear trend, the HP filter generates a non-linear presentation by a procedure of squared error minimization. The differences in the correlations of deviations from the two types of trends are not statistically significant in most cases. Linear trends are more sensitive to short-run fluctuations than the HP filter trends.

However, the differences between the absolute values of the simple correlations and the corresponding de-trended correlations can be very large. For example, the differences between the simple correlations and the related linear-detrended correlations are 0.723 for Korea versus the United States during 1976-1980, 0.672 for Malaysia versus the United States during the same period, 0.567 for Thailand versus the United States during 1981-1984, 0.676 for Malaysia versus the United States during 1989-1991, and 0.731 for Taiwan versus the Eurozone during 1992-1996. The differences between the simple correlations and the corresponding Hodrick-Prescott filter detrended correlations are 0.732 for Korea versus the United States during 1976-1980, 0.692 for Malaysia versus the United States during the same period, and 0.527 for Taiwan versus the United States during 1992-1996. The differences between simple correlations and the correlations of deviations from the linear trend are less than $0.15,80 \%$ of the time for the US and $75 \%$ for the Eurozone, and are greater than $0.25,10.42 \%$ of the time for the US and $8.33 \%$ for the Eurozone. Meanwhile, differences between simple correlations and the correlations of deviations from the Hodrick-Prescott trend are less than $0.15,70 \%$ of the time for the US and $52 \%$ for the Eurozone, and are greater than $0.25,12.5 \%$ of the time for the US and $20.83 \%$ for the Eurozone.

The values of real GDP correlations reflect the expected results based on structural characteristics. China, Taiwan, Hong Kong, and especially Singapore and Thailand display relatively high average correlations with the United States and the Eurozone during the different time periods, consistent with their export-led growth strategies. China, as the Asian center for assembly, has made great contributions in promoting the growth of other Asian countries, such as Malaysia, the Philippines, and India, by importing intermediate goods from these countries for export to the United States and the Eurozone. In the 2000s, as trade barriers gradually decreased for most Asian economies, the correlations with the United States became positive and increased by various 
degrees. Japan, Singapore, Malaysia, Indonesia, Hong Kong, and Taiwan experienced dramatic increases in the first half of the 2000s. Japan, the only industrialized economy in Asia, was able to quickly absorb the information in the world market and enjoyed first-mover advantage benefits from globalization and trade liberalization. This may explain high correlations with the US during 1985-1988 and 2001-2005. China's entry into the World Trade Organization (WTO) was also followed by an increase in the comovement with the US. During the 2000s, high correlations with the US and the Eurozone, in general, indicate an increased interdependence of Asian economies with United States and Europe, rather than decoupling, although evidence of low correlations can also be found during some of the time frames.

To assess intra-correlations of business cycles over longer time frames, four sub-period contemporaneous correlations for cyclical parts were calculated, for linear detrended correlations and for Hodrick-Prescott filter detrended correlations. The cyclical parts are derived by applying the linear-de-trending technique and the Hodrick-Prescott filter de-trending technique. Columns highlighted in shade show the correlations which are 0.50 or greater for the corresponding country pairs.

Using the linear de-trending technique, during the first sub-period (1976-1984), countries such as China and India recorded very low and even negative correlations with the others, except with Taiwan and the US for China, which indicates some degree of divergence in real output fluctuations. Overall, this result is robust when the Hodrick-Prescott filter detrended technique is used. During 1976-1984, five out of 11 correlations for China were negative, and eight out of 11 for India were negative. But, in the second sub-period (1985-1996), India had only three of 11 negative correlations with other countries, while Japan and China each had seven. Hong Kong had the most correlations above 0.50 with other countries in the period of 1976-1984, however this number decreased from five to two out of 11 in the period of 1985-1996. In contrast, during the periods 1997-2007 and 1999-2007, correlations increased considerably after the 1997-1998 Asian Crisis. In the post-crisis period, 33 out of 78 cases of intra-correlations above 0.50 are observed, compared to only 14 out of 66 cases prior to the crisis. China, Hong Kong, Japan, Singapore, Malaysia, Thailand, and Taiwan increased their correlations with other countries in the periods of 1997-2007 and 1999-2007. Furthermore, East Asian countries, especially ASEAN, have seemed to increase integration among themselves and with Japan since 1997.

To investigate the decoupling hypothesis, the correlations with the United States and the Eurozone on these four different sub-periods were compared. From the first sub-period (1976-1984) to the second sub-period (1985-1996), most of the Asian economies other than India experienced decreased correlations with the United States, signaling the possibility of decoupling. During the third sub-period (1997-2007), most of the Asian countries displayed increased correlations with the US, except for China, India, Indonesia, and the Philippines. This could serve as evidence of decoupling for China and India from the United States. However, during the fourth sub-period (1999-2007), all of the Asian countries had increased correlations with the United States and the Eurozone, which supports recoupling of these Asian economies with the United States and the Eurozone, rather than the decoupling hypothesis.

For robustness, the Hodrick-Prescott filter de-trending technique was also used. Generally speaking, similar results were obtained. This may reflect the end-point issue of the Hodrick-Prescott filter detrending technique, in which the calculation puts heavier weight on the observations in the end of the series. To be specific, one notable difference is that China only has one to two cases of intra-correlations above 0.50 with other countries after the Asian crisis, far less than the results using the linear de-trending technique. Another 
different result obtained by using the Hodrick-Prescott de-trending technique was that more Asian countries' business cycles were correlated with the United States and the Eurozone, with higher correlations than when using the linear de-trending technology. One more difference is that when excluding the data of the 1997-1998 Asian crises, the pairwise correlations generally increase, rather than decrease in the case of linear de-trending.

Based on the above analysis, it is not reliable to place a great deal of weight on using correlations over short periods to support or reject the decoupling hypothesis. In addition to being variable, short-run correlations are generally not statistically significant. Theoretically, the increased globalization and economic interdependence will facilitate the growth of international trade flows and the substantial increase of international capital mobility. However, the high variability in correlations over time suggests that the expected results have been muted by the variability in shock patterns.

\section{Empirical Results of Dynamic Factor Models}

Figure 1 displays the output variance decomposition. As shown, the world factor plays an important role in explaining output variance, especially for industrialized economies and developed Asian economies, such as the United States, Hong Kong, Singapore, Thailand, Taiwan, and Japan, compared with other Asian emerging market economies. Due to limited space, only figures for part of the output variance decomposition are presented here. Other figures for variance decomposition are omitted. However, the explanatory power of the world factor declines to various degrees from the pre-1985 period to post-1985 period, except for South Korea, Malaysia, and the Philippines. Surprisingly, the regional factor of North America accounts for $13.13 \%$ of the explanation of output fluctuations of the United States. The possible explanation for this phenomenon could be the increase in trade integration between the United States and Canada, mainly through intra-industry trade. Compared with other countries in the dataset, the explanatory power of regional factors to output variance in Indonesia, Japan, the Philippines, Taiwan, Singapore, and the United States increased with different magnitudes for each country in the sample: from $1.97 \%$ to $3.03 \%$ for Indonesia, $1.82 \%$ to $3.17 \%$ for Japan, $2.30 \%$ to $3.05 \%$ for the Philippines, $0.67 \%$ to $1.48 \%$ for Taiwan, $0.93 \%$ to $1.86 \%$ for Singapore, and $13.13 \%$ to $15.69 \%$ for the United States. However, the regional effects remain quite small for all Asian countries. Country factors contribute largely to explaining output variance in Asian emerging market economies in the pre-globalization period, especially for China, Hong Kong, Indonesia, and Malaysia, which have explanatory proportions of country factors above $40 \%$. On the whole, the explanatory power of country factors for output variance increases for most of the countries in the sample in the second sub-period, except for Japan and the Eurozone.

Domestic consumption variance decomposition for each country reveals that the world factor also plays an increasingly important role in explaining domestic consumption variance for most of the economies in the system, except for Japan, Malaysia, and Thailand. At the same time, the share of domestic consumption variance attributable to the world factor goes up overall in the post-1985 globalization period, compared with that in the pre-1985 globalization period. The substantial increases happen in the Philippines, the United States, and Singapore, from $1.53 \%$ to $25.06 \%, 2.30 \%$ to $19.35 \%$, and $0.31 \%$ to $1.87 \%$, respectively. Compared with the world factor, regional factors play a relatively less important role in explaining average domestic consumption fluctuations. The influence of regional factors on domestic consumption increases for China, Hong Kong, Malaysia, India, Singapore, Thailand, Taiwan, and the United States from the first sub-period to the second sub-period, especially for China and Thailand, from $2.31 \%$ to $8.19 \%$ and $1.29 \%$ to $8.12 \%$, respectively. In general, the share of domestic consumption variance attributable to country factors is larger 
than that of the world factor. The importance of the country factors attributable to consumption variance decreases in the second sub-period for China, Hong Kong, India, South Korea, Malaysia, Singapore, Thailand, and the United States in different magnitudes: from $23.66 \%$ to $8.58 \%$ for China, $33.72 \%$ to $19.34 \%$ for Hong Kong, $8.45 \%$ to $7.07 \%$ for India, $54.29 \%$ to $14.19 \%$ for South Korea, $30.43 \%$ to $22.65 \%$ for Malaysia, $57.94 \%$ to $25.17 \%$ for Singapore, $18.19 \%$ to $10.29 \%$ for Thailand, and $43.46 \%$ to $38.14 \%$ for the United States. During this time, the importance of country factors increases for Indonesia, Japan, the Philippines, and Taiwan. For Japan, $60 \%$ fraction of variance in consumption is attributable to country factors, which is the highest in the system.

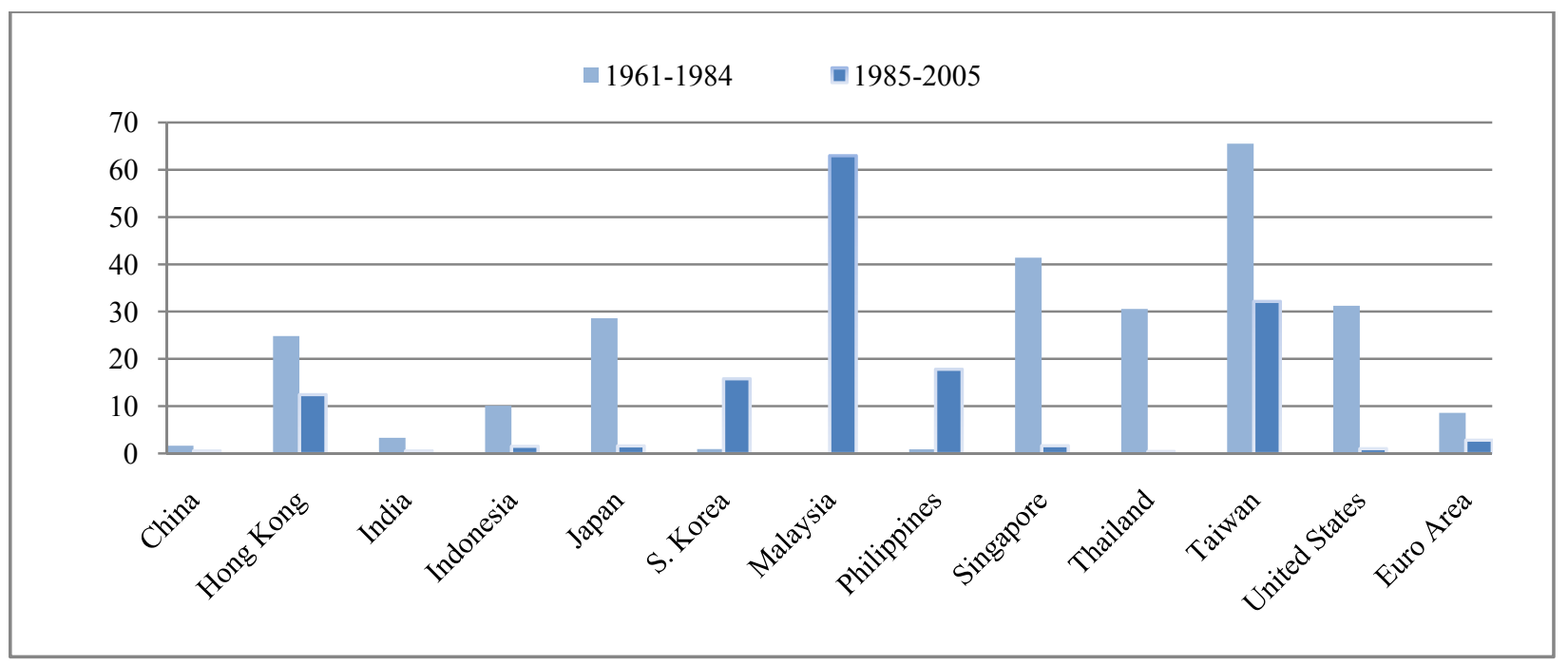

Figure 1. Output variance explained by world factor (fraction of variance).

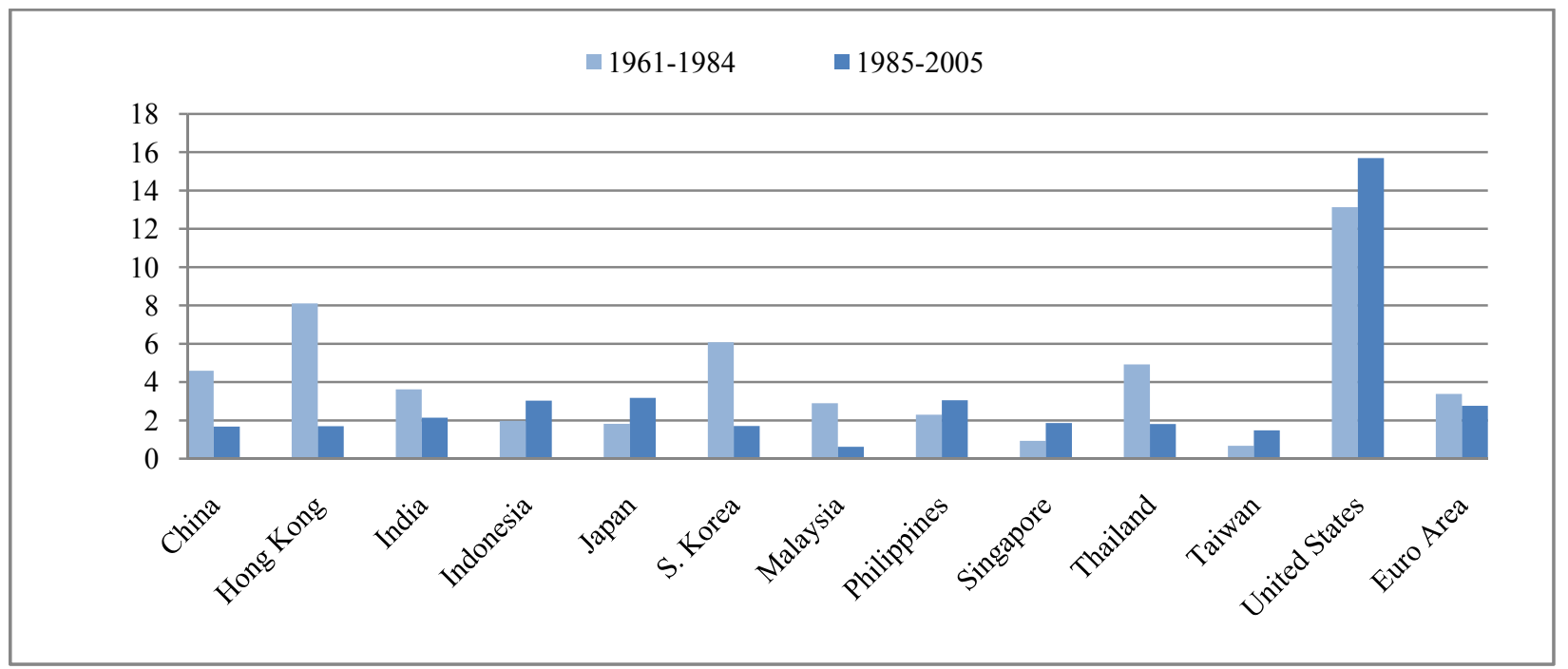

Figure 2. Output variance explained by regional factors.

For the domestic investment variance decomposition for individual countries, the share of investment variance attributable to the global factor declined in the post-1985 globalization period from $9.69 \%$ to $0.34 \%$ for Taiwan, $3.79 \%$ to $0.76 \%$ for Japan, $2.53 \%$ to $0.20 \%$ for Malaysia, and $13.05 \%$ to $0.80 \%$ for Singapore. However, the simple average variance of investment explained by the world factor does not change from the 
pre-1985 globalization period to the post-1985 globalization period. On average, the share of investment variance attributable to regional factors decreases from $4 \%$ to $3.5 \%$, and from $31 \%$ to $18 \%$ for country factors. This is consistent with the conclusion in the standard stochastic dynamic business cycle models, that generally speaking, as trade and financial linkages become stronger, lower investment correlations across countries will be induced. Reduced restrictions on capital and current account transactions should lead to more "resource shifts", through which capital and other resources could rapidly move to different countries with more favorable technology shocks (Kose et al., 2008).

For the variance decomposition of gross exports and gross imports at the country level, the share of gross exports variance attributable to world factor declines in a majority of countries, besides Indonesia, South Korea, the Philippines, Singapore, and Taiwan. For example, it declined from $7.69 \%$ to $0.29 \%$ for China, $10.94 \%$ to $1.60 \%$ for the United States, and $17.19 \%$ to $1.71 \%$ for the Eurozone. Explanations for the decreases in the United States and the Eurozone from the pre-1985 globalization period to the post-1985 globalization period may be related to increased regional integration in North America and the Eurozone, respectively. The world factor influences the gross export variance in greater proportion for Hong Kong, Japan, South Korea, and Malaysia, than other countries in the system. On average, export variance is $25 \%$ in the pre- 1985 globalization period and $15 \%$ in post-1985 globalization period. Regional factors have become less important in explaining the gross export fluctuations for most of the countries, except for Hong Kong, Singapore, and Taiwan. Overall, the importance of regional factors in explaining the gross exports is decreasing for the United States, the Eurozone, developed Asian economies (including Hong Kong, Japan, Korea, Malaysia, Singapore, Thailand, and Taiwan), and developing Asian economies (including China, India, Indonesia, and the Philippines). The decrease in the share of gross exports that is attributable to regional factors is relatively larger in the United States and developing Asian group than in the Eurozone and developed Asia, indicating that the process of trade and financial integration weakens the role of regional factors in explaining gross export fluctuations. In addition, country factors become more important in post-1985 globalization period for the United State and all 11 Asian economies in the system.

The explanatory power of the world factor for gross imports decreased for most of the countries, for instance, from $10.39 \%$ to $0.47 \%$ for China, $4.59 \%$ to $0.30 \%$ for Hong Kong, and $9.43 \%$ to $0.23 \%$ for Indonesia, while the share of gross imports variance attributable to the world factor increased for India, Malaysia, Japan, Thailand, and the United States in different magnitudes, from $0.97 \%$ to $1.11 \%$ for India, $0.52 \%$ to $4.59 \%$ for Japan, $0.31 \%$ to $1.51 \%$ for Malaysia, and $1.02 \%$ to $1.85 \%$ for the United States. On the whole, the explanatory power of the world factor for gross imports is increasing in the United States, decreasing in the Eurozone and developing Asia, and has remained relatively constant in developed Asia from the pre-1985 globalization period to the post-1985 globalization period. In general, the regional factors have become less important in explaining the variance of gross imports in different regions. For the individual countries, the shares of the regional factors attributable to gross imports decreased in the post- 1985 globalization period for most of the countries, for example, from $3.73 \%$ to $0.59 \%$ for Hong Kong, $12.52 \%$ to $1.15 \%$ for India, and $14.72 \%$ to $0.78 \%$ for Japan. Additionally, country factors have become more important in explaining gross import fluctuations for most of the countries except for India, Malaysia, and Thailand in the post-1985 globalization period. From the perspective of the different regions, the explanatory power of country factors increased for the United States, the Eurozone, developed Asia, and developing Asia.

To summarize the results for variance decompositions using dynamic factor models for the 11 Asian 
economies, plus the United States and the Eurozone, there are three major findings for sub-period 1961-1984 (pre-globalization period) and sub-period 1985-2007 (post-globalization period).

First of all, a world factor of the business cycle exists, since there is a significant common-world component in the fluctuations of almost all of the countries in the sample system. According to the results of previous studies, a substantial fraction of economic fluctuations are explained by the world factor in developed economies, such as the United States and the Eurozone, while the country factors and idiosyncratic components account for more of the volatility in most of the developing economies, such as China and India. Based on the author's results, this world factor accounts for a modest but significant share of macroeconomic fluctuations, in terms of the difference in logarithms of output growth, consumption growth, investment growth, export growth, and import growth, although the world factor is more important in explaining business cycles in developed countries, such as the United States and the Eurozone. However, the explanatory power of the world factor decreased from the first sub-period 1961-1984, to the second sub-period 1985-2006. At the average level, as globalization and regional integration increase, the explanatory power of the world factor and regional factors is expected to increase in explaining macroeconomic aggregate fluctuations from the pre-globalization period to the post-globalization period. However, domestic consumption was the only factor that confirmed this expectation. This is a puzzle, since the correlations for these countries were high in recent years. To explore this mystery requires further research. For other aggregates, country factors still contribute to a relatively large portion of the aggregate fluctuations explanation.

Second, given the world factor, regional factors for Asian countries, and the Euro area do not play an important role in explaining the macroeconomic aggregate volatility, as they do for the North America region. For the United States, the regional factor accounts for a substantial share of the variances from gross exports and gross imports. Furthermore, the explanatory power of regional factors decreases from the pre-globalization period to the post-globalization period. However, when the world factor is excluded, the share of macroeconomic variance attributable to regional factors becomes increasingly important on the whole. The purpose of suppressing the world factor is to check the existence and the importance of the world factor by comparing the difference between the results with and without the world factor. The results of suppressing the world factor also serve as the robustness check for the regional factor, as well as the discussion of the ability for regional factors to capture variances when the world factor is excluded. At the average level, regional factors and country factors play a more important role in explaining gross import fluctuations than in explaining gross export fluctuations. This result is as expected, since gross import is a function of domestic income, while gross export is a function of foreign income.

Third, domestic consumption and domestic investment variances are primarily driven by country and idiosyncratic factors. Particularly, country dynamic factors play a key role in explaining consumption fluctuations, compared with the world and regional factors, which is consistent with imperfect risk sharing among countries. Output fluctuations are expected to be explained by increasing country factors in the post-globalization period. Results found that, on average, the fraction of output variance attributable to country factors increased. Considering the components of output $Y=C+I+G+(X-M)$, the explanatory power of country factors to domestic investment decreases, the explanatory power of country factors to gross exports and gross imports increases, and the explanatory power of country factors to domestic consumption remains generally consistent. The net effects of country factors on output variance depend on the relative magnitudes of the increase and decrease of the output components. 
It is natural that the world factor seems to be important, and it could more accurately reflect economic activities in the developed countries. In contrast, developing economies are more likely to experience country cycles.

\section{Conclusion and Policy Implications}

This paper explores the decoupling hypothesis in East Asia by using standard correlation approaches and dynamic factor models to complement each other, considering that both methods have their own advantages and disadvantages. As trade integration deepens among Asian countries, business cycle synchronization among these countries is expected to increase through trade transmission. Based on previous estimation frameworks, data of the United States and the Eurozone were added to avoid biases from the world factor. The results of the standard correlation approaches indicate that intra-industry trade serves as the major channel through which business cycles become synchronized among selected countries, although increased trade measured by trade intensity does not necessarily lead to more correlated business cycles (Shin \& Wang, 2003).

Based on the correlation analysis, some evidence exists for the convergence of ASEAN and ASEAN +3 in intra-Asian, and the decoupling of Asian economies from the United Stated and the Eurozone. However, it is not reliable to place a great deal of emphasis on short-run correlations to either support or reject the decoupling hypothesis, because the results have high variability, depending on the length of the period and the patterns of the shocks. In addition, short-run correlations are typically not statistically significant. Theoretically, increased globalization and economic interdependence will facilitate the growth of international trade flows and substantial international capital mobility. Moreover, the high variability in correlations over time suggests that the expected results have been muted by the variability in patterns of shocks, which may be decomposed into a global factor, group-specific or regional factors, country factors, and idiosyncratic factors. But, each of these factors may also have different patterns of shocks.

According to dynamic factor models for the evolution of global business cycle linkages, the world factor has become less important in explaining the macroeconomic fluctuations from sub-period 1961-1984 to sub-period 1985-2007. The regional factors play a less important role in explaining aggregate volatility during the latter sub-period than the former, except for in the North America region. This is contrary to the popular view of increased regional macroeconomic interdependence in Asia. Domestic consumption variances are often attributable to country factors and regional factors, and domestic investment variances are primarily driven by country and idiosyncratic factors, compared with the world factor. The increasing explanatory power of regional factors for consumption echoes the common perception that Asia has become much more integrated at the macroeconomic level in recent years, but this does not hold for other macroeconomic aggregates, such as domestic output, domestic investment, gross exports, and gross imports. At the same time, regional factors and country factors also play a more important role in explaining gross import fluctuations than in explaining gross exports. These results are as expected, since gross import is a function of domestic income, while gross export is a function of foreign country income. It is also found that the country factors and idiosyncratic factors account for a great portion of investment volatility.

As mentioned by Kose (2002) and Kose et al. (2008), from a policy perspective, understanding changes in the nature of the global business cycles is of considerable interest in a number of respects. If Asian integration is more substantial than globalization, regional factors should be focused on. However, if the influence from the United States is substantial in explaining the dynamics of business cycles, the world factor should be of greater 
focus. The need for regional and global coordination is derived from spillover effects associated with interdependence. The trade channel is an important source of these spillovers. Regional coordination refers to coordination between different countries which are not necessarily important at the global level, but that have a high degree of structural interdependence with each other. In the case of the Asia region, regional interdependence in East Asia is deepening, mainly through the structural vertical intra-industry trade channel.

It is a mystery that the substantial increase in intra-industry trade in Asia should increase the importance of the regional factor there, on average. However, that is found in the correlation analysis but not the dynamic factor estimation. Therefore, the results from both methods are not consistent with each other. To explore this puzzle requires further study. One possible direction is to take into account the channel of capital flow transmission and the overlapping parts between international trade and international finance.

\section{References}

Athukorala, P., \& Kohpaiboon, A. (2009). East Asian exports in the global economic crisis: The decoupling fallacy and post-crisis policy challenges. The Australia National University, Working Papers in Trade and Development. Working Paper No. 2009/13.

Baxter, M., \& Kouparitsas, M. A. (2005). Determinants of business cycle comovement: A robust analysis. Journal of Monetary Economics, 52(1), 113-157.

Frankel, J. A., \& Rose, A. K. (1998). The endogeneity of the optimum currency area criteria. Economic Journal, 108(449), 1009-1025.

Giovanni di, G., \& Levchenko, A. A. (2009). International trade and aggregate fluctuations in granular economies. 2009 Meeting Papers 491, Society for Economic Dynamics.

Kose, M. A. (2002). Explaining business cycles in small open economies: How much do world prices matter. Journal of International Economics, 56, 299-327.

Kose, M. A., Otrok, C., \& Prasad, E. S. (2008). Global business cycles: Convergence and decoupling? IMF Working Paper, WP/08/143.

Otrok, C., \& Whiteman, C. H. (1998). Bayesian leading indicators: Measuring and predicting economic conditions in Iowa. International Economic Review, 39(4), 997-1014.

Shin, K., \& Wang, J. (2003). Trade integration and business cycle synchronization in East Asia. The Institute of Social and Economic Research, Osaka University, 6-1 Mihogaoka, Ibaraki, Osaka 567-0047, Japan.

Willett, T. D., Liang, P., \& Zhang, N. (2011). Chapter 9 global contagion and the decoupling debate. In C. Yin-Wong, K. Vikas, and M. Guonan (Eds.), The Evolving Role of Asia in Global Finance (Frontiers of Economics and Globalization, Volume 9 , pp. 215-234), Emerald Group Publishing Limited. 